\title{
CORRELAÇÃO ENTRE CONTAMINAÇÃO GASTROINTESTINAL E PRESENÇA DE Salmonella spp. EM CARCAÇAS DE FRANGO INDUSTRIALIZADAS NO RIO GRANDE DO SUL
}

\author{
Ana Paula Dutra Resem Brizio ${ }^{1}$, Leonardo Werlang Isolan $^{2}$, Bruna Salles $^{3}$, Carlos Prentice ${ }^{1}$ \\ ${ }^{1}$ Universidade Federal do Rio Grande (FURG), Rio Grande, RS, Brasil. e-mail: anabrizio@ yahoo.com.br \\ ${ }^{2}$ Médico Veterinário - Fiscal Federal Agropecuário do Ministério da Agricultura Pecuária e Abastecimento (MAPA) \\ ${ }^{3}$ Médico Veterinário - Prefeitura Municipal de Lajeado, RS, Brasil. Inspeção de Unidade Produtora de Carne de Ave
}

\section{RESUMO}

O presente trabalho teve como objetivo avaliar a incidência de contaminação gastrointestinal visível em carcaças industrializadas de frango na etapa de evisceração e verificar a relação com a presença de Salmonella spp. em carcaças após o sistema de pré-resfriamento. $\mathrm{O}$ estudo foi realizado em um abatedouro sob inspeção federal, localizado no Estado do Rio Grande do Sul, no período de julho de 2011 a abril de 2012. Foram avaliados registros de ocorrência de contaminação gastrointestinal visível, em um total próximo de $8,5 \times 10^{7}$ carcaças de aves, e a incidência de Salmonella spp. em 357 amostras. O resultado médio de contaminação gastrointestinal visível foi de 3,37\% $\pm 0,61$, enquanto o percentual de prevalência de Salmonella spp. foi de $0,57 \% \pm 0,83$. Através do teste de correlação, utilizando o programa Statistica 7.0 $(\mathrm{p}<0,05)$, foi possível constatar que não houve relação significativa entre as variáveis estudadas $(\mathrm{p}=0,4959)$. Os resultados apontaram que as operações de abate e processamento de aves foram realizadas de forma sanitária, através do controle das Boas Praticas de Fabricação (BPF), o que propiciou baixos índices de presença de Salmonella spp. nas amostras.

Palavras-chave: BPF, carcaça de frango, contaminação visual, patógeno

\section{CORRELATION BETWEEN GASTROINTESTINAL CONTAMINATION AND THE PRESENCE OF Salmonella Spp. IN POULTRY CARCASSES INDUSTRIALIZED IN RIO GRANDE DO SUL STATE, BRAZIL}

\begin{abstract}
This study aimed to evaluate the incidence of visible gastrointestinal contamination in poultry industrialized carcasses during evisceration and verify its relation with the presence of Salmonella spp. in carcasses after the prechiller tank. The study was conducted in a slaughterhouse under federal inspection, located in Rio Grande do Sul State, Brazil, from July 2011 to April 2012. Records on the occurrence of visible gastrointestinal contamination were analyzed, in a total close to $8,5 \times 10^{7}$ poultry carcasses, and the incidence of Salmonella spp. was analyzed in 357 samples. The average result of visible gastrointestinal contamination was $3.37 \%$ \pm 0.61 , while the prevalence percentage of Salmonella spp. was $0.57 \pm 0.83 \%$. No significant relationship between the variables studied was found $(\mathrm{p}=0.4959)$, as determined by the correlation test using the program Statistica $7.0(\mathrm{p}<0.05)$. The results showed that the operations of poultry slaughter and processing were performed in sanitary conditions through the Good Manufacturing Practices (GMP) control, which resulted in low levels of Salmonella spp. in the samples.
\end{abstract}

Key words: GMP, poultry carcasses, visible contamination, pathogen 


\section{INTRODUÇÃO}

Segundo a UBABEF (2011) a carne de frango tem se consolidado como uma das mais importantes fontes de proteína animal para a população brasileira, onde o consumo per capita atingiu 44Kg em 2010, apresentando um incremento de 5,6\% em relação ao ano anterior. Associado a isso, houve um aumento de $11,4 \%$ na produção de carne de frango no Brasil, o que garantiu a terceira posição no ranking mundial entre os países produtores.

Estas informações evidenciam a importância da produção avícola para o mercado brasileiro de carnes. Juntamente com o aumento desta produção, ressaltam-se as crescentes exigências do mercado consumidor com relação à segurança do produto ofertado.

De acordo com Isolan (2007), qualidade e segurança no processamento industrial é o grande interesse de produtores, consumidores e fiscais em saúde pública no mundo inteiro. A avicultura brasileira, por sua vez, tem se mostrado atenta a estas exigências de mercado, preocupando-se com os aspectos nutricionais e higiênico-sanitário dos alimentos.

A etapa de evisceração é considerada um dos principais pontos críticos da cadeia produtiva de frango, pois durante a mesma pode ocorrer o rompimento das vísceras, resultando em contaminação cruzada de bactérias de origem gastrointestinal, dentre elas, a Salmonella (Vasques, 2006).

Em vista disso, o Ministério da Agricultura, Pecuária e Abastecimento (MAPA) estabelece legislações específicas como o regulamento da inspeção industrial e sanitária de produtos de origem animal (Brasil, 1952) e mais recentemente, o "Programa de redução de patógenos (PRP)", por meio da instrução normativa (IN) 70 (Brasil, 2003).

O regulamento da inspeção industrial e sanitária de produtos de origem animal
(Brasil, 1952) determina os critérios visuais para a avaliação post mortem das carcaças na etapa de evisceração. Por sua vez, o PRP é um programa que executa análise laboratorial sistemática e contínua de carnes in natura de aves, para a pesquisa de Salmonella spp. na saída do sistema de préresfriamento (Brasil, 2003).

Conforme Tessari et al. (2008), o PRP atua como componente importante no controle sobre o processo de abate e atendimento às exigências de segurança do alimento, baseado nos princípios de Boas Práticas de Fabricação (BPF).

$\mathrm{O}$ presente trabalho teve como objetivo avaliar a incidência de contaminação gastrointestinal visível em carcaças industrializadas de frango na etapa de evisceração e verificar a relação com a deteç̧ão de Salmonella spp. em carcaças após o pré-resfriamento.

\section{MATERIAL E MÉTODOS}

Esta pesquisa foi desenvolvida em um abatedouro de aves sob inspeção federal, situado no estado do Rio Grande do Sul, Brasil. A capacidade de abate é de 500.000 animais por dia, realizada em dois turnos diários.

A etapa de evisceração é efetuada de forma automática, através de equipamentos específicos em três linhas independentes de evisceração, cada uma com capacidade para 10.000 carcaças por hora.

Este estudo compreendeu o período de julho de 2011 a abril de 2012, avaliando registros de ocorrência de contaminação gastrointestinal visível durante a etapa de evisceração e a incidência de Salmonella spp. no final do sistema de pré-resfriamento. Seguindo a instrução normativa 70 (Brasil, 2003), obteve-se 7 ciclos amostrais no período (Tabela 1). 
Tabela 1. Padronização das coletas de amostras por ciclo.

\begin{tabular}{cccc}
\hline \multirow{2}{*}{ Ciclo } & Período de Amostragem & \multicolumn{2}{c}{$\mathrm{N}^{\mathbf{o}}$. de carcaças coletadas } \\
\cline { 3 - 4 } & & Análise visual & Salmonella \\
\hline 1 & $21 / 07 / 11-25 / 08 / 11$ & 12.024 .206 & 51 \\
2 & $26 / 08 / 11-04 / 10 / 11$ & 12.047 .267 & 51 \\
3 & $04 / 10 / 11-11 / 11 / 11$ & 12.005 .299 & 51 \\
4 & $11 / 11 / 11-19 / 12 / 11$ & 11.972 .272 & 51 \\
5 & $20 / 12 / 11-24 / 01 / 12$ & 12.067 .059 & 51 \\
6 & $24 / 01 / 12-28 / 02 / 12$ & 12.104 .087 & 51 \\
7 & $29 / 02 / 12-03 / 04 / 12$ & 12.239 .564 & 51 \\
Total & & 84.459 .754 & 357 \\
\hline
\end{tabular}

A instrução normativa 70 (Brasil, 2003) regulamenta a coleta de 1 amostra por turno para um abate diário superior a 100.000 aves. O conjunto formado por 51 amostras colhidas ao acaso $(n=51)$ é denominado "ciclo de amostragem", no qual o máximo de positivo aceitável são 12 amostras (c=12), perfazendo $21 \%$.

Para a análise de Salmonella spp., foi utilizada a metodologia descrita em American Public Health Association APHA (2001). A análise visual das carcaças seguiu os critérios determinados pelo regulamento da inspeção industrial e sanitária de produtos de origem animal (Brasil, 1952).

Utilizou-se o teste de correlação para verificar a relação entre a contaminação gastrointestinal visível e a incidência de Salmonella spp., através do software Statistica 7.0, com um índice de significância de $95 \%(\mathrm{p}<0,05)$.

\section{RESULTADOS E DISCUSSÃO}

Os resultados percentuais de contaminação gastrointestinal visível e análises laboratoriais de Salmonella spp. foram agrupados em ciclos amostrais (Tabela 2).
O resultado médio apresentado de contaminação gastrointestinal visível foi de $3,37 \% \pm 0,61$ no período avaliado. Pela falta de padrões legais para este índice, o mesmo é analisado internamente pelas unidades fabrís através de histórico de contaminação e estabelecimento de meta. No abatedouro estudado o padrão interno de contaminação gastrointestinal permitido é de no máximo $8 \%$. Resultados de pesquisas apontam valores superiores de contaminação visível em carcaças de frango quando comparados aos encontrados neste estudo. Russel (2003) constatou um percentual máximo de contaminação visual de $34 \%$ nas suas amostras, enquanto Smith et al. (2007) relataram que houve ruptura dos intestinos durante o processo de evisceração em 5,5 a $25,2 \%$ das carcaças de frango avaliadas.

De um total de 07 ciclos amostrais foi detectada a presença de $2 \%$ de Salmonella spp. nos ciclos 01 e 07, índices que atendem ao limite legal de $21 \%$ (Brasil, 2003). O percentual de prevalência global de Salmonella spp. foi de $0,57 \% \pm 0,83$, resultados com valores superiores foram encontrados por Tessari et al. (2008), os quais verificaram a prevalência de 2,5\% deste patógeno em carcaças resfriadas no estado de São Paulo. 
Tabela 2. Valores experimentais de contaminação visual e Salmonella.

\begin{tabular}{ccc}
\hline Ciclo & \% Contaminação visual & \% Salmonella \\
\hline 01 & 3,7 & 2 \\
02 & 3,5 & 0 \\
03 & 2,1 & 0 \\
04 & 3,1 & 0 \\
05 & 3,8 & 0 \\
06 & 3,8 & 0 \\
07 & 3,6 & 2 \\
\hline
\end{tabular}

É interessante observar que trabalhos realizados anteriormente ao surgimento do Programa de Redução de Patógenos (PRP) revelaram percentuais de isolamento de Salmonella spp. superiores aos observados neste estudo. Tessari et al. (2003) relataram a presença deste organismo em 13 das 68 $(19,8 \%)$ amostras de frango analisadas e Almeida Filho et al. (2003) encontraram 18 amostras de $40(45,0 \%)$ contaminadas pelo patógeno. Fuzihara et al. (2000) obtiveram $42,0 \%$ de positividade para Salmonella em carcaças de frango processadas industrialmente. Santos et al. (2000), que pesquisaram Salmonella spp. em 150 carcaças de frangos congeladas, encontraram $32 \%$ de contaminação.

Bersot (2006) relatou que a construção de sistemas de monitoramento microbiológico faz com que as indústrias se preocupem ainda mais em controlar rigorosamente medidas sanitárias e tecnológicas, o que pode ser observado comparando-se os dados obtidos neste estudo, com aqueles publicados antes do programa de redução de patógenos ser instituído.

Através do teste de correlação, utilizando o "software" Statistica 7.0 $(\mathrm{p}<0,05)$, foi possível constatar que não houve relação entre a incidência de contaminação gastrointestinal visível e as análises de Salmonella spp. O resultado encontrado para as amostras foi $\mathrm{p}=0,4959$, apresentando uma correlação baixa, já que os valores percentuais são considerados significativos quando menores que $5 \%$ $(\mathrm{p}<0,05)$.

De acordo com Galarz et al. (2010), a ocorrência e a quantidade de Salmonella spp. presentes na carne de aves variam de acordo como os cuidados sanitários durante o processamento das carcaças. Para Carvalho \& Cortez (2005) é possível a contaminação bacteriana, especialmente por Salmonella, que se encontra no trato intestinal, contaminar as carcaças caso o processo de abate não seja realizado adequadamente.

Conforme Mead (1974) a etapa de evisceração é muito propícia para o aumento da contaminação nas carcaças uma vez que a abertura da cavidade celomática e exposição das vísceras podem provocar a ruptura destas causando contaminação da carcaça. Corroborando, Soares et al. (2002) observaram que na carcaça pós-evisceração, ocorreu um aumento no número de enterobactérias quando comparado com as outras etapas do processamento, o que reforça a opinião de Walsh \& Thayer apud Soares et al. (2002), quando relatam que um dos maiores problemas no processamento de frangos é a contaminação das carcaças por matéria fecal durante a etapa de evisceração. 
A instrução normativa 70 (Brasil, 2003) preconiza que o sistema de inspeção seja realizado em conjunto com práticas de garantia de qualidade, baseado nos princípios de Boas Práticas de Fabricação durante todas as etapas do processamento. Os resultados apontam que a empresa onde o presente estudo foi conduzido possui estas práticas bem implementadas, mantendo um controle minucioso sobre o processo, o que propiciou baixos índices de Salmonella spp. em carcaças.

Apesar da baixa prevalência de Salmonella spp. nas amostras avaliadas, o risco à saúde dos consumidores, bem como as perdas econômicas associadas a este micro-organismo, tornam relevante $\mathrm{o}$ contínuo monitoramento e implementação de programas de redução de patógenos em alimentos.

\section{CONCLUSÃO}

Não houve correlação $(\mathrm{p}<0,05)$ entre
a incidência de contaminação
gastrointestinal visível em carcaças
industrializadas de frango na etapa de
evisceração e os achados de Salmonella spp.
em carcaças após o pré-resfriamento,
resultados que confirmam que o
estabelecimento avaliado atende às
exigências das legislações vigentes.

\section{REFERÊNCIAS BIBLIOGRÁFICAS}

ALAMEIDA FILHO, E. S.; SAMPAIO, S. C. O.; BORGES, N. F.; DELMONDES, E. C.; OZAKI, A. S.; SOUZA, L. C. 2003. Pesquisa de Salmonella spp. em carcaças de frango (Gallus gallus), comercializadas em feira livre ou em supermercado no município de Cuiabá, MT, Brasil. Higiene Alimentar, v.17, n.110, p.74-79.

APHA - American Public Health Association. 2001. Compendium of Methods for the Microbiological
Examination of Foods. Washington. DC, $676 \mathrm{p}$.

BERSOT, L. S. 2006. Efeito do préresfriamento em chiller sobre a contaminação superficial de carcaças de frango. In: CONGRESSO BRASILEIRO DE MEDICINA VETERINÁRIA，29，2006. Gramado, RS. Anais: Sociedade de Veterinária do Rio Grande do Sul, n.183.

BRASIL. 1952. Ministério da Agricultura e Abastecimento. Decreto no 30.691/1952. Regulamento da Inspeção Industrial e Sanitária de Produtos de Origem Animal (RIISPOA).

BRASIL. 2003. Ministério da Agricultura e Abastecimento. Instrução Normativa $\mathbf{n}^{\mathbf{0}}$ 70/2003. Programa de Redução de Patógenos - $\quad$ Monitoramento Microbiológico e Controle de Salmonella sp. em Carcaças de Frangos e Perus.

CARVAlHO, A. C. F. B.; CORTEZ, A. L. L. 2005. Salmonella sp. em carcaças, carne mecanicamente separada, lingüiças e cortes comerciais de frango. Ciência Rural, v.35, n.6, p.1465- 1468.

FUZIHRA, T. O.; FERNANDES, S. A.; FRANCO, B. D. 2000. Prevalence and dissemination of Salmonella serotypes along the slaughtering process in Brazilian small poultry slaughterhouses. Journal of Food Protection, v. 63, p.1749-1753.

GALARZ, L. A.; FONSECA, G. G.; PRENTICE-HERNÁNDEZ, C. 2010. Crescimento microbiano em produtos à base de peito de frango durante simulação da cadeia de abastecimento. Ciência e Tecnologia de Alimentos, v.30, n.4, p.870-877.

ISOLAN, L. W. 2007. Estudo da eficiência da etapa de pré-resfriamento por imersão em água no controle da qualidade microbiológica das carcaças de frango. Dissertação de mestrado - Curso de Pósgraduação em Ciências Veterinárias, 
Universidade Federal do Rio Grande do Sul (UFRGS), Porto Alegre-RS, 87 p.

MEAD, G, C. 1974. Bacteriological control in the processing of poultry. Veterinary Record, v. 95, p. 569-572.

RUSSEL, S. M. 2003. The effect of airsacculitis on bird weights, uniformity, fecal contamination, processing errors, and populations of Campylobacter spp. and Escherichia coli. Poultry Science, v. 82, p.1326-1331.

SANTANA, A. P.; MURATA, L. S.; FREITAS, C. G.; DELPHINO, M. K, PIMENTEL, C. M. 2008. Causes of condemnation of carcasses from poultry in slaughterhouses located in State of Goiás, Brazil. Ciência Rural, v.38, n.9, p.2587-2592.

SANTOS, D. M. S.; BERCHIERI JUNIOR, A.; FERNANDES, S. A.; TAVECHIO, A. T.; AMARAL, L. A. 2000. Salmonella em carcaças de frango congeladas. Pesquisas Veterinárias Brasileiras, v.20, n.1, p.39-42.

SMITH, D. P.; NORTHCUTT, J. K.; CASON, J. A.; HINTON, J. R. A.; BUHR, R. J.; INGRAM, K. D. 2007. Effect of External or Internal Fecal Contamination on Numbers of Bacteria on Prechilled Broiler Carcasses. Poultry Science, v.86, n.6, p. 1241-1244.

SOARES, J.; BENNITEZ, L. B.; TERRA, N. N. 2002. Análise de pontos críticos no abate de frangos através da utilização de indicadores microbiológicos. Higiene Alimentar, v.15, n.95, p. 53-61.

TESSARI E. N. C.; CARDOSO, A. L. S. P.; CASTRO, A. G. M.; ZANATTA, G. F. 2003. Prevalência de Salmonella enteritidis em carcaças de frango industrialmente processadas. Higiene Alimentar, v. 17, n.107, p.52-55.

TESSARI, E. N. C.; SICCHIROLI, A. L.; CARDOSO, P.; KANASHIRO, A. M. I.; STOPPAI, G. F. Z.; LUIS, R.; CASTRO, L. A. G. M. 2008. Ocorrência de Salmonella spp. em carcaças de frangos industrialmente processadas, procedentes de explorações industriais do estado de São Paulo, Brasil. Ciência Rural, v.38, n.9, p. 2557-2560.

UBABEF. 2011. União Brasileira de Avicultura. Relatório Anual 2010/2011. Disponível em: <http://www.abef.com.br/ubabef/publica coes_relatoriosanuais.php $>$. Acesso em: 29 mai 2012.

VASQUES, O. J. T. 2006 Evisceração. In: OLIVO, Rubison (Comp.). O mundo do frango. Criciúma. Editora do Autor, Cap. 18. p. 221-229. 